\title{
Práticas de saúde entre prostitutas de segmentos populares da cidade de Santa Maria-RS: o cuidado em rede
}

| ${ }^{1}$ Priscila de Oliveira Bolzan Bonadiman, 2 Paula Sandrine Machado,

${ }^{3}$ Laura Cecilia López I

Resumo: O artigo apresenta resultados de pesquisa sobre percepções e práticas de saúde entre prostitutas de bares da cidade de Santa Maria, Rio Grande do Sul. Para tanto foram investigados, através de técnicas de observação participante e de entrevistas semiestruturadas, as práticas e os cuidados de saúde dessas mulheres e a forma como se relacionam com os serviços de saúde. Entre as mulheres, no contexto pesquisado, foi identificado um "cuidado em rede" como estratégia de cuidado com a saúde, o qual é acionado em diferentes situaçóes, como as que envolvem o cotidiano do trabalho. Conclui-se que as redes estabelecidas excedem o nível individual de cuidado, configurando produção de conhecimento em saúde, bem como se articulam decisivamente como resposta a vulnerabilidades, socializando práticas e contornando dificuldades.

\author{
${ }^{1}$ Mestrado em Saúde Coletiva \\ pela Universidade do Vale do \\ Rio dos Sinos (UNISINOS); \\ enfermeira no Hospital \\ Universitário de Santa Maria \\ (HUSM) da Universidade \\ Federal de Santa Maria \\ (UFSM). Endereço eletrônico: \\ pri_bolzan@yahoo.com.br \\ ${ }^{2}$ Mestrado e doutorado em \\ Antropologia Social pela \\ Universidade Federal do \\ Rio Grande do Sul (UFRGS); \\ professora do Departamento de \\ Psicologia Social e Institucional e \\ do Programa de Pós-Graduação \\ em Antropologia Social da \\ UFRGS. Endereço eletrônico: \\ machadops@gmail.com \\ Mestrado e doutorado em \\ Coletiva da UNISINOS. EndereçO \\ eletrônico: lauracl@unisinos.br
} vulnerabilidades; cuidado em rede. 


\section{Introdução}

Este artigo apresenta os resultados de pesquisa ${ }^{1}$ que teve como objetivo investigar as percepções e práticas de saúde de prostitutas de segmentos populares que exercem sua atividade em bares da cidade de Santa Maria, Estado do Rio Grande do Sul. São analisadas as percepções das mulheres sobre sua atividade e sobre as condiçôes em que a desempenham, bem como os mecanismos utilizados na promoção de saúde.

O estudo insere-se no campo da Saúde Coletiva e discute questôes relacionadas ao modo como essas mulheres estão acessando e sendo acessadas pelos serviços de saúde de atenção primária da cidade - visto que estes são a porta de entrada de todo o sistema de saúde. Busca-se, assim, refletir sobre como estão sendo encaminhadas as demandas dessas mulheres.

O tema da prostituição tem sido amplamente abordado a partir de diferentes perspectivas (OLTRAMARI; CAMARGO, 2005; GUIMARÃES; MERCHÁN-HAMANN, 2005; BARRETO, 2008). Sobretudo no campo das ciências sociais, têm-se ampliado as perspectivas de análise, desnaturalizando-se pressupostos relacionados à prostituição. Ganham visibilidade os intensos debates sobre a regulamentação da profissão a partir das considerações sobre as relações e práticas estabelecidas nesse contexto (PASINI, 2000; 2005; PISCITELLI, 2007; RUSSO, 2007; TEDESCO, 2008; BLANCHETTE; SILVA, 2009; COLVERO, 2010; RODRIGUES, 2009; OLIVAR, 2010).

Estudos em diferentes contextos têm destacado as distintas relações que as prostitutas estabelecem com seus corpos. Guimarães \& Merchán-Hamann (2005) apontaram para o corpo da prostituta como recurso de trabalho utilizado por elas na venda de fantasias eróticas. Adriana Piscitelli (2007) abordou a construção da erotização no mercado do sexo contemporâneo a partir de uma análise de gênero e corporalidade. José Miguel Olivar (2010) refere os saberes e poderes de prostitutas sobre seus corpos, aprendidos nas suas trajetórias de vida e também no cotidiano da própria prostituição.

Em sua pesquisa com prostitutas de rua da cidade de São Paulo, Elisiane Pasini (2000) identificou as práticas corporais como um divisor entre a esfera da prostituição e as outras dimensões da vida das mulheres. A autora identificou importante categoria, relacionada ao corpo, que emerge na perspectiva da tríade "higiene-saúde-doença": as mulheres que participaram do estudo de 
Pasini (2000) possuíam intensa preocupação com a higiene do corpo, a qual simbolizava uma forma de cuidado com a saúde. Deste modo, ainda que não realizassem visitas frequentes a médicos, os cuidados com a higiene eram uma das maneiras de cuidado com a saúde.

$\mathrm{O}$ presente artigo se insere, assim, no conjunto dessas produções que abordam as relações entre prostituição, corpo e saúde, e busca problematizar as práticas e o acesso à saúde no contexto da prostituição. Ele está organizado em torno de dois eixos temáticos. O primeiro trata das práticas de saúde entre as mulheres. $\mathrm{O}$ segundo, das vulnerabilidades relatadas por elas - incluindo-se aqui suas relações com os serviços de saúde - ou observadas em situações de campo.

Valemo-nos da noção de rede, entendida como uma teia de interações entre sujeitos envolvidos em ações concretas (BRAGA, 2006), para pensar os cuidados com a saúde e o corpo relatados pelas entrevistadas. Estudos na área da Saúde Coletiva têm focado as redes de cuidados disseminadas a partir dos serviços de saúde (BONET; TAVARES, 2006; BRAGA, 2006; PINHEIRO; GUIZARDI, 2008). Embora a "rede cuidadora" não se restrinja a esses serviços, mas abarque a articulação com outros recursos da sociedade, como apoio familiar, religiosidade, alternativas de sustentação econômica, laços de solidariedade e outros que compõem as chamadas "redes sociais de apoio" (SILVA; ALVES; ALVES, 2005, p. 86), estas últimas não aparecem como o foco principal das pesquisas. De maneira diferencial, o artigo parte da perspectiva da sociedade civil na constituição da rede de cuidados e os vínculos de solidariedade que a sustentam.

Vale esclarecer que, embora no artigo seja utilizado o termo "prostituta" para fazer referência às mulheres, durante o período em que foi realizada a pesquisa observou-se que elas acionavam dois termos para se autodenominarem: "prostituta" e "profissionais do sexo". Seu uso alternado, contudo, não era sem tensões e dependia, conforme se pôde identificar no decorrer do trabalho de campo, do contexto e do que estava em jogo na situação.

O uso de "profissional do sexo" era mais utilizado entre as mulheres no sentido de amenizarem o estigma que sentiam dirigir-se a elas em função da atividade, como se o termo lhes conferisse determinado valor - talvez vinculado à palavra "profissional" - que a palavra "prostituta" não o fazia. Conforme esclareceu uma das mulheres em entrevista: "acho que profissional do sexo fica melhor, prostituta eu acho... eu acho meio baixo, sabe? Profissional do sexo é melhor.” 
(Raquel, 40 anos, 15 anos na prostituição). Já a utilização de "prostituta", além de ser o termo referenciado pela Rede Brasileira de Prostitutas, indo ao encontro dos ensejos de profissionalização, parece representar para elas força e afirmação, sendo mais acionado em situações de repúdio ao preconceito. Como reforça outra das mulheres entrevistadas: "não acho que sirvo pra outra coisa, sempre foi isso, sou prostituta mesmo.” (Regina, 31 anos, 12 anos na prostituição).

\section{Metodologia e contexto da pesquisa}

Esta pesquisa foi realizada em Santa Maria, cidade de médio porte, que abriga quase 300 mil habitantes, sendo aproximadamente 30 mil flutuantes em função do grande número de instituições de ensino superior, federal e privado, situadas no município.

Em relação à prostituição, pode-se dizer que a cidade possui características de cidades de grande porte, muito embora não existam em Santa Maria organizações ou associações de prostitutas, geralmente presentes em capitais ou grandes aglomerados. Considerando-se o estudo de Ana Paula da Silva e Thaddeus Blanchette (2009), na cidade do Rio de Janeiro, Santa Maria assemelha-se a essa capital no sentido da diversidade na oferta de serviços. Em sua pesquisa, os autores identificam nove estilos básicos de ponto: desde casas e boates, passando por bares, até pontos de prostituição de rua. Chamam a atenção, ainda, para a existência do que definem como duas categorizações morais da prostituição - a prostituição de elite e a trash -, as quais ressoariam as tradicionais divisões de alto e baixo meretrício. Da mesma forma, em Santa Maria há serviços de prostituição que perpassam boates mais luxuosas e apartamentos até bares populares e pontos de rua, ou seja, há serviços contemplando os mais variados preços e segmentos sociais.

Para a presente pesquisa, foi utilizado o método etnográfico, de junho a dezembro de 2009. Além da observação participante em bares e boates, foram realizadas oito entrevistas semiestruturadas ${ }^{2}$ em lugares diversificados, conforme a possibilidade das entrevistadas. $\mathrm{O}$ universo empírico da pesquisa formou-se por mulheres pertencentes a segmentos populares ${ }^{3}$ que trabalham com prostituição em bares, em horários que se iniciam no meio da manhã e vão até o final da tarde, estendendo-se, por algumas vezes, até a noite. Em relação aos clientes, também pertencem a segmentos populares e, segundo a fala delas, a maioria é casado ou com companheira. Os bares foram escolhidos por se assemelharem no que diz respeito 
ao seu modo de funcionamento e clientela. As mulheres entrevistadas foram eleitas

por afinidade, disponibilidade para responder à entrevista e pela própria dinâmica do trabalho de campo, que foi criando oportunidades e momentos.

Sabe-se que a manutenção de casa de prostituição e a prática de rufianismo são crimes condenados pelo Código Penal Brasileiro. Dessa forma, é importante indicar que os bares onde foi realizada a pesquisa não se consideravam "casas de prostituição", nem mesmo declarava-se haver, por parte do dono do estabelecimento, cobrança de dinheiro relacionada a "programas" realizados no bar. Sobre essa questão, era esclarecido que nos bares existiam quartos e que eram "cobrados" aluguéis no caso de sua utilização por determinado tempo.

Quanto às oito mulheres entrevistadas, suas idades variaram entre 28 e 55 anos de idade no momento da pesquisa. No que diz respeito ao estado civil, dividiam-se entre solteiras, com companheiro fixo/namorado, casada ou separada. Todas as entrevistadas possuíam filhos e já haviam desempenhado outras atividades como fonte de renda - empregada doméstica e babá estão entre elas. A escolaridade variou entre o primeiro grau incompleto e o segundo grau incompleto. Em relação ao tempo em que trabalhavam com prostituição, houve diferenças significativas: durante as entrevistas, uma referiu estar há mais de dez anos na atividade, enquanto outra há menos de meio ano. Essa grande variação no tempo de prostituição foi encontrada não só em relação às entrevistadas, mas no contexto geral da pesquisa.

No modo de vestir, elas em geral usavam jeans e blusa, sapatos comuns - altos ou baixos -, no rosto havia sempre algum batom, lápis, rímel ou sombra discreta e as unhas estavam, na maioria das vezes, bem feitas e pintadas. Os cabelos, geralmente bem penteados. Não se notavam diferenças evidentes que pudessem ser percebidas entre essas mulheres daquelas que circulavam pelas proximidades dos bares e que não exerciam a prostituição. Contudo, os clientes não pareciam ter dificuldades na identificação das mulheres. $\mathrm{O}$ modo como gesticulam e, por vezes, o tom alto de voz que utilizam funcionam como indicativos. Além disso, assim como o observado por Colvero (2010), o fato de estarem nesses bares bebendo cerveja sozinhas e aceitarem que algum homem as acompanhasse era uma das formas de permitir essa identificação, por exemplo.

A pesquisa foi realizada em seis estabelecimentos, localizados entre o centro e a região oeste da cidade. Todos possuem características semelhantes no que 
concerne a suas estruturas físicas e à dinâmica de funcionamento. São locais de estrutura pequena e luz diminuída. Nas paredes predominam cartazes, geralmente de propagandas de cerveja com mulheres de biquíni. Todos os bares tocam música alta, na maioria das vezes vinda de máquinas coloridas e cheias de luzes. Elas funcionam movidas a dinheiro, ou seja, coloca-se uma moeda e podese escolher a música a tocar. $\mathrm{O}$ estilo de música frequentemente varia entre os sucessos do brega pop e o sertanejo. Em geral, são músicas para “dançar junto”, do estilo calypso e sertanejo universitário.

Os bares são "comandados" por um dono - homem - que é o responsável pela ordem no local, prevenindo brigas entre fregueses, prostitutas ou entre fregueses e prostitutas. Há sempre um balcão, no qual o dono do bar ou alguém de sua confiança pode ser encontrado. O balcão é também o local onde, na maior parte das vezes, encontram-se os preservativos e géis lubrificantes que os bares recebem da prefeitura municipal. Os quartos alugados para realização dos programas localizam-se ao fundo dos bares, onde também são encontrados banheiros, que as prostitutas utilizam quando necessitam e, principalmente, entre os programas, com fins específicos, mais bem detalhados adiante.

\section{Prostitutas de segmentos populares e práticas de saúde: a noção de cuidado}

As práticas em relação ao corpo e à saúde, observadas e referidas pelas mulheres durante a pesquisa, podem ser interpretadas como conformando uma rede de cuidados que expressam as relações entre as prostitutas, como mostraremos a seguir.

As mulheres referiram estratégias de cuidado, as quais foram relacionadas com a promoção da saúde e bem-estar. Em conversas informais com Joana e Lílian, elas relataram, respectivamente, razões que as motivam a ter cuidados com seu corpo e aparência, e a influência do exercício da prostituição nesses cuidados:

Eu me cuido, cuido da minha aparência, do meu corpo, pra poder me sentir bem, e também pra trabalhar e render bem. Tento estar sempre com as unhas feitas, pintadas, o cabelo arrumado, cheirosa, isso é importante pra mim. Os clientes até perguntam se eu sou menor de idade, pelo meu corpo! Duvidam que eu tenha dois filhos, quando eu conto! (Joana, 28 anos, dois anos na prostituição).

Olha, depois que eu comecei a trabalhar com isso, comecei a me cuidar mais, me arrumar mais. Nada de exageros, mas tu achas que antes eu cuidava assim do cabelo, lavava, secava, fazia chapinha? Capaz! (Lílian, 30 anos, dois anos na prostituição). 
Os cuidados com a saúde e o bem-estar puderam ser compreendidos a partir das seguintes categorias: cuidados que vêm de casa e que são aprendidos no contexto da família; cuidados adquiridos na vida, que advêm da própria experiência na atividade e do convívio entre as prostitutas; e cuidados ensinados por algum/a profissional dos serviços de saúde.

Na primeira categoria, enquadram-se práticas como o exercício do "se lavar" após as relaçōes sexuais que, segundo elas, apesar de ser comum entre prostitutas, é algo a ser praticado por qualquer pessoa, e que representa um costume que vem de casa, sendo passado, inclusive, de mãe para filha no momento em que essa passa a manter relações sexuais. Essa prática é caracterizada pelo ato de lavar os órgãos genitais após as relações sexuais. Joana e Raquel, falando dessa prática nas entrevistas, ressaltam, respectivamente:

Entre os programas eu sempre cuido pra me lavar no banheiro, porque mesmo com camisinha, sabe como é, no calor, o suor e tudo, tem que se lavar um pouco, se ajeitar pra voltar [...] (Joana, 28 anos, 02 anos na prostituição)

Eu uso camisinha e tento me cuidar, me lavo bem e faço minhas duchas bem profundas com o chuveirinho, e te digo que nunca tive problemas desses de DSTs. [...] Minha mãe já fazia (as duchas), coisa de família. E eu tento ensinar minha filha, digo pra ela fazer, ela tem esses probleminhas às vezes, esses corrimentos, e eu digo pra ela fazer as duchas que é bom, porque lava tudo lá dentro. (Raquel, 40 anos, 15 anos na prostituição).

Outro hábito relatado por algumas das mulheres entrevistadas e tido por elas como um cuidado aprendido em casa refere-se à prática de manter-se depilada, como um cuidado íntimo relacionado à higiene, e também à sedução:

Me depilo desde novinha e acho que a mulher tem que estar bem depiladinha! Aquele monte de pelos pra quê? Fica muito mais bonito e é melhor pra cuidar, pra limpar. (Raquel, 40 anos, 15 anos na prostituição).

Quanto às questôes de cuidado com a higiene, Pasini (2000) encontrou em seu estudo essa preocupação com o corpo por parte das prostitutas. Suas entrevistadas revelavam, por exemplo, lavar com duchas as partes do corpo que entraram em contato com os clientes após o programa. Esse cuidado é entendido pelas mulheres de duas maneiras: relacionado a uma maneira de distinguir as relações que mantinham com seus companheiros e com seus clientes - como modo de demarcar fronteiras entre as diferentes relações - e enquanto forma de cuidar da saúde.

Cabe a consideração de que os cuidados citados pelas mulheres como hábitos de higiene - o "se lavar" e o uso de duchas vaginais - podem ser entendidos de 
maneira complexa, referindo-se não só às estratégias de cuidado com o próprio corpo, mas também ao delineamento simbólico de fronteiras morais. O imaginário em torno da prostituta como aquela que personifica o "corpo doente" projetado pelo comércio do sexo pode ser considerado para entender essa recorrência de preocupações em torno da higiene (BARRETO, 2008). Isso nos leva a refletir sobre como esses cuidados de promoção do próprio bem-estar podem operar também em relação aos estigmas que recaem sobre a mulher prostituta como moralmente "impura". Assim, pode-se interpretar que esses sentidos coexistem no universo estudado. Lavar-se entre os programas pode representar tanto uma prática de bem-estar e saúde para a mulher, quanto um comportamento de separação do que não faz sentido levar para si do programa com o cliente o mau cheiro, possíveis secreções. Além disso, lavando-se após cada programa, também reforçam suas posturas como profissionais, ou seja, valorizando uma boa apresentação e aparência, importantes para a conquista do próximo cliente e continuidade do trabalho.

A segunda categoria relacionada ao cuidado refere-se àquele definido como aprendido na vida. Esses são os cuidados aprendidos e compartilhados entre as prostitutas. Em conversas durante tardes de trabalho de campo nos bares, pudemos ouvir histórias nas quais as mulheres trocavam dicas sobre, por exemplo, o uso do gel lubrificante. O gel - usualmente utilizado para facilitar o ato sexual - estende sua função desde protetor do cabelo contra o cheiro de cigarro e hidratante até recurso erótico no momento do programa, conforme expressado por Sandra, em conversa no bar onde trabalha:

Esse gel tem inúmeras finalidades! Lá na hora com o homem eu gosto de colocar um pouquinho no peito, eu passo assim, só no bico, porque aí ele fica durinho e os homens gostam! (Sandra, 37 anos, nove anos na prostituição).

Assim, práticas como o uso do gel, compartilhadas entre essas mulheres, parecem tanto auxiliar e/ou facilitar o desempenho individual da atividade, quanto criar laços entre elas, favorecendo a constituição de uma rede de cuidados. A seguir, a fala de Lílian, em entrevista, demonstra outra situação:

Ah, uma coisa que eu sempre faço é tomar banho, antes e depois. Nem que seja lavar um pouco. [...] As gurias dão toques... Mas, mais foi de olhar, ficar cuidando assim, observando as outras. (Lílian, 30 anos, dois anos na prostituição). 
Percebe-se, nesse momento, que são falas diferentes. Enquanto uma representa uma prática que é compartilhada informalmente entre as mulheres, a outra se refere a uma prática aprendida no cotidiano do trabalho através da observação do comportamento das colegas. Embora diferentes, em ambos os casos a situação se apresenta de maneira que mulheres com menor tempo de prostituição aprendam cuidados praticados por mulheres com mais tempo.

Juliana Cavilha (2011) observou, em sua pesquisa de doutorado, que o êxito na carreira dessas mulheres se liga intimamente a arranjos formados entre colegas de profissão, em que as com mais tempo de experiência e maior conhecimento dos "segredos" da profissão se organizam informalmente, de modo a passar as informaçōes às mais novas.

As práticas de cuidado com o próprio corpo, fortalecidas ao serem reiteradas por essas mulheres, podem ser interpretadas ainda como forma de reação contra algumas adversidades do trabalho, como o frequente cheiro do cigarro, característico dos bares, somado à baixa ventilação de ar que apresentam. Nesse caso, o uso do gel nos cabelos, por exemplo, pode ser considerado como uma estratégia a ser utilizada e passada adiante. Desse modo, os conhecimentos são compartilhados em uma rede que as ajuda frente a contextos de vulnerabilidades.

Um olhar mais detido nos mostra ainda que esses laços, a princípio aparecendo como amistosos, também são perpassados por conflitos. Ora parceiras, ora rivais, esse relacionamento explicita a complexidade da dinâmica das relações no ambiente de trabalho e evidencia que existem vínculos de solidariedade, mas que essas parcerias podem se formar e dissipar de acordo com o contexto.

Um exemplo dessa ambiguidade nas relações é o caso de Vanessa (29 anos, oito anos na prostituição) que, grávida do marido preso, permaneceu indo ao bar ainda que não estivesse fazendo programas naquele período. Alegava sentirse bem no local, pois passava o tempo conversando com as colegas. Além disso, no bar, Vanessa sempre era premiada com um ou outro lanche, regalias dadas pelas colegas que se comoviam diante da situação financeira e emocional difícil pela qual passava a moça. Durante uns dias, Vanessa até permaneceu na casa de Sandra, onde ganhou comida e roupas novas da colega. Essa relação de parceria entre as duas mulheres foi interrompida após Vanessa ganhar o bebê. Segundo Sandra, as duas se desentenderam, pois Vanessa havia acusado Sandra - que a 
estava ajudando a juntar fraldas - de demorar a entregar as mesmas. A situação virou desavença e Sandra passou a desconsiderar a amizade de Vanessa em função da falta de confiança: "Imagina se eu vou pegar as fraldas dela! O que eu quero com fralda?! Se eu que estava pedindo pra ajudar ela..." (Sandra, 37 anos, nove anos na prostituição).

Conforme aponta Cynthia Sarti em sua pesquisa em torno das relações familiares em grupos populares nas periferias de São Paulo: "neste jogo de espelhos que caracteriza a elaboração de identidades sociais, há ambivalência dos moradores em relação a seus pares [...]. Num processo que não é unívoco, solidariedade e rivalidade caminham juntas." (SARTI, 1996, p. 92). No que se refere às relações entre as mulheres na prostituição, esse tipo de relação foi descrita também por Elisiane Pasini: "[...] ouvi muitas vezes que na rua não se tem amigas, se tem colegas. Mas observei, em diferentes momentos, práticas imbuídas de companheirismo, principalmente relacionado às mulheres que compartilhavam do mesmo ponto de prostituição" (PASINI, 2000, p. 72).

Além das tensões que permeiam suas relações de companheirismo e amizade, podemos mencionar também as ambiguidades das relações como colegas de trabalho. Conforme coloca Paulo Dantas em artigo sobre sua pesquisa antropológica na Vila Mimosa: “elas são 'amigas' entre si, mas desde que uma não tire o possível cliente da outra” (DANTAS, 2002, p. 1).

Situações como essas se expressavam cotidianamente no universo da presente pesquisa, a exemplo do dia em que Mariza (36 anos, 11 anos na prostituição) contou, em uma tarde chuvosa, que apesar do pouco movimento no bar não pôde chegar em nenhum dos homens que haviam entrado há pouco no estabelecimento e se encontravam sem acompanhante ainda, pois eles já eram "clientes fixos" de outras colegas e que se "chegar é briga na certa". A disputa por clientes, característica de sua profissão, é intensamente permeada por sentimentos diversos, do respeito à inveja. Por motivos variados, as brigas e desentendimentos entre colegas são situações comuns no contexto da prostituição, sendo a disputa por clientes um dos mais recorrentes (PASINI, 2000). Essa relação ambígua vaise expressando cotidianamente nas alternâncias de momentos de rivalidade com períodos de união/parceria, como no dia em que encontramos as meninas em um dos bares juntando dinheiro para comprar um lanche em conjunto em um mercado que havia próximo ao bar. Observa-se assim que essas relações acabam configurando uma rede, flexível e mutável ao longo do tempo e do contexto. 
O universo da prostituição, pode-se dizer, constitui-se de relações variadas.

Olivar (2011) discorre, por exemplo, sobre a rede configurada a partir da própria organização política das prostitutas no Brasil, numa lógica de confiança/ desconfiança, com relações constituídas em meio a alianças temporárias e conflitos constantes.

A terceira e última categoria referente à noção de cuidado diz respeito àquele ensinado por algum(a) profissional pertencente a um serviço de saúde. Essa categoria inclui as atitudes nas quais os serviços tentam adaptar suas ações no sentido de atender às demandas das prostitutas, com atuaçóes percebidas por elas como despidas de preconceito e imposiçōes. O dia em que Carmen (55 anos, seis meses na prostituição) recebeu orientações de uma profissional da saúde sobre como diminuir o desconforto do sexo anal configura um exemplo claro desse cuidado adaptado. Carmen conta que a profissional havia explicado que ela poderia "encharcar a camisinha de gel e fazer uma ducha após o sexo anal, seguida do uso de uma pomadinha quando estiver doída". Da mesma forma, pode-se considerar o relato de Sandra (37 anos, nove anos na prostituição) sobre o uso do preservativo feminino de maneira diferenciada, sugestão de sua médica: "durante o sexo oral, coloca a camisinha feminina no pênis do homem, que é maior que a outra e protege mais, dá mais cobertura."

Estudo recente da Associação Brasileira Interdisciplinar de Aids (ABIA, 2011) analisou as diretrizes da política brasileira de prevenção e atenção à saúde de mulheres prostitutas no contexto do HIV/Aids. Dentre as principais considerações, foi possível verificar que, a partir dos anos 80, as políticas nacionais obtiveram êxito no que diz respeito à abertura de espaço e visibilidade para essas mulheres, mas que, num sentido mais amplo, os serviços de saúde ainda hoje permanecem bastante restritos no que concerne às necessidades das prostitutas. Tal consideração concorda com o que foi encontrado em campo na presente pesquisa, já que, embora presente, o diálogo com os profissionais de saúde apareceu em intensidade menor do que os outros diálogos aqui apontados, o que sinaliza necessidade de reflexóes.

Ainda assim, pode-se dizer que uma rede de cuidados também é traçada entre prostitutas e serviços de saúde, no interior da qual também são produzidos e transmitidos conhecimentos sobre saúde. Sejam originadas pela família, pela própria prostituição ou por algum serviço de saúde, essas práticas apresentam- 
se como um "cuidado em rede". As redes, conformando o pano de fundo onde se desenrolam as açôes, "estabelecem uma superfície de contato que possibilita, nas negociações cotidianas, a interpenetração de diferentes saberes que se associam aos usos distintivos do corpo e a uma diferente economia das emoções" (BONET; TAVARES, 2006, p. 389).

Nesse sentido, entendemos que os cuidados relatados pelas mulheres pesquisadas conformam uma rede e produzem agenciamentos em relação à saúde. Baseados na experiência, esses conhecimentos e práticas aparecem como importantes no seu cotidiano na medida em que parecem conferir maior poder de resposta às adversidades que o contexto em que realizam sua atividade lhes proporciona.

\section{Refletindo sobre vulnerabilidades}

Ayres et al. (2003), ao definirem vulnerabilidade, abordam-na como resultado de aspectos coletivos e contextuais relacionados a uma maior ou menor possibilidade de exposição à doença. Refere-se, ainda, de maneira intrínseca, à maior ou menor disponibilidade de recursos protetivos. Sendo assim, pode-se dizer que ela é multidimensional e variável.

No contexto da vulnerabilidade, há três eixos, articulados entre si, que a compõem: o eixo individual-aliando componentes cognitivos e comportamentais; o eixo social - referente ao acesso às informaçōes e aos recursos; e o eixo programático - que diz respeito aos programas institucionais de prevenção e cuidado. Assim, parte-se do pressuposto de que ninguém é vulnerável, mas pode estar vulnerável, dependendo de certas condiçôes (AYRES et al., 2003).

Sobre a prostituição feminina, Olivar (2010) refere algumas dificuldades observadas no exercício da atividade que, em maior ou menor intensidade, acabam interferindo na vida dessas mulheres: exposição frequente a problemas da saúde sexual / reprodutiva decorrentes de DSTs, abortos mal praticados, estimulação assídua ao uso - por vezes abusivo - de álcool e outras drogas no âmbito do trabalho, ausência de uma assistência ampla e necessária de estratégias de redução de danos. ${ }^{4}$

Partindo-se da noção de contextos de vulnerabilidade, conforme descrito acima, o presente estudo aponta: 1) vulnerabilidades relacionadas às práticas, ao ambiente e às relaçôes estabelecidas no trabalho e 2) vulnerabilidades relacionadas às condições de acesso a saúde. 
Refere-se aqui aos recursos de trabalho, ao ambiente dos bares e às relações traçadas no contexto da prostituição como fatores que podem configurar contextos de vulnerabilidade em saúde entre as mulheres, em uma análise a partir de situaçôes singulares que se apresentaram durante a pesquisa.

O uso frequente de álcool e cigarro no dia a dia dos bares foram os elementos referidos pelas mulheres participantes da pesquisa como recursos de trabalho prejudiciais à saúde. Assim, no momento da entrevista, quando questionadas se existia alguma característica relacionada ao trabalho que pensavam prejudicar sua saúde, o uso constante e/ou contato direto com esses artefatos foi comentado:

O fato de eu beber todos os dias é uma coisa que eu penso que, por mais que eu tente beber pouco, até pra não prejudicar o meu ganho, têm dias que a voz fica rouca... E tem também o cheiro do cigarro, que mesmo que eu não fume, eu sinto sempre, toda hora, aquele cheiro forte. E fica na roupa e no cabelo! (Raquel, 40 anos, 15 anos de prostituição).

A bebida não me faz bem, mas a gente bebe, não adianta, a gente acaba bebendo, tá ali... (Vanessa, 29 anos, oito anos de profissão).

Diante disso, algumas mulheres relataram lançar mão de estratégias para amenizar os efeitos do uso do álcool. Lílian (30 anos, dois anos de prostituição) referiu: "têm as cervejas mais fracas que dá pra beber mais, sem ficar mal. E também, a gente não precisa beber tudo que servem, dá pra enganar, jogar fora...”. Percebe-se, assim, que mesmo diante de circunstâncias em que os recursos de trabalho podem desfavorecer, são acionadas estratégias que tentam contorná-las.

Em relação ao ambiente de trabalho, destacam-se considerações a respeito dos quartos, salão e banheiro, que são o espaço por onde circulam as mulheres desta pesquisa quando se encontram no bar. Sendo assim, o estado de conservação desses ambientes também remete ao cuidado com a saúde das prostitutas. Sobre isso, foram relatadas queixas, conforme depoimento a seguir, de uma mulher jovem e com pouco tempo de prostituição: "os dois quartos estão sujos! Cada um tem um banheirinho, mas o sabonete, me diz, cadê? Ele [o dono do bar] até põe, mas já sumiu...."

Além disso, as mulheres também se queixam bastante das condições dos lençóis, pelo fato de não serem trocados frequentemente. Entretanto, da mesma forma que o álcool, também revelaram artifícios para lidar com a situação, como o uso de toalhas sobre a cama, que melhoram as condições para exercerem seus programas. 
Como ressalta Raquel (40 anos, 15 anos na prostituição): “[...] quem é que vai se sentir bem deitando naqueles lençóis que lá de vez em quando se troca? Eu levo uma toalha, que tenho na bolsa, e estendo encima da cama pra me deitar".

$\mathrm{O}$ ato de estender a toalha como medida protetiva ao deitar-se na cama, realizado de maneira individual, torna-se compartilhado, na medida em que é uma prática de cuidado com o corpo socializada entre essas mulheres. Tanto nessa situação como no ato de se proteger do consumo excessivo de álcool, aciona-se o cuidado em rede, na medida em que são conhecimentos que circulam entre essas mulheres no seu cotidiano profissional e que as fortalecem frente a contextos de vulnerabilidades.

No que se refere à forma como são traçadas as relações no cotidiano da prostituição nesses bares e a forma como as mesmas podem estar vinculadas a vulnerabilidades em saúde, merece atenção a relação entre as prostitutas e o dono do bar onde trabalham.

A figura do dono do bar aparece de maneira ambígua: ele é aquele que ajuda quando auxilia na compra de remédios, por exemplo -, mas também é alguém que pode dificultar - como em algumas situações nas quais representa um empecilho para o acesso a preservativos. Em um dos bares onde foi realizada observação participante, a caixa de preservativos fornecidos pela Política Municipal em Hiv/ Aids do município ao estabelecimento costumava ficar em uma gaveta no balcão do bar. Quando o dono se ausentava - por minutos que fosse - trancava a gaveta com chave, impossibilitando o acesso àqueles preservativos e criando, assim, dificuldades para as mulheres que contavam com eles.

Durante uma tarde de trabalho de campo, uma das mulheres contou satisfeita ter conseguido, após conversa com o dono do bar, modificar o lugar da caixa de preservativos para um local de livre acesso. Essas constantes negociaçôes apontam para o fato de que os modos de relação estabelecidos com o dono do bar demarcam posições de poder que podem repercutir em maior vulnerabilidade dessas mulheres. Assim, ainda que de maneira diferenciada, o dono do bar também é parte constituinte dessa rede.

A relação que se desdobra entre prostitutas e clientes também merece considerações. A esse respeito, Regina (31 anos, 12 anos na prostituição) relata, informalmente, durante conversa sobre a dificuldade de convencer alguns clientes para o uso do preservativo masculino: "[...] às vezes, tem homem que se 
aproveita. Quando a gente tá meio tontinha e no escuro, eles tiram a camisinha na hora e a gente vê só depois quando termina".

Sobre essa situação, quando questionada se não havia percebido que a relação fora sem camisinha, ela respondeu que "na hora da empolgação, não! E ainda meio bêbada...”. Moura et al. (2010) referem que entre as mulheres que mantinham uma relação fixa com alguns clientes, alguns exigiam que o preservativo não fosse usado. Dessa forma, apresenta-se a ideia de estabilidade que o parceiro fixo representa, com a sensação de sexo seguro. Outros fatores presentes no referido estudo relacionam-se às propostas que as prostitutas recebem para o não uso do preservativo: a oferta de maior remuneração pelo programa ou, ainda, situações em que a ausência do preservativo é associada à "empolgação", em casos de uso de drogas em excesso ou baixa autoestima (MOURA et al., 2010).

\section{Condições de acesso à saúde}

$\mathrm{O}$ acesso à saúde para as prostitutas foi, por muito tempo, pontualmente marcado por tentativas de controle e medidas higienicistas (BARRETO, 2008). Com a implementação do Sistema Único de Saúde (SUS), tentativas foram e continuam sendo feitas para atender com equidade a essa população/público.

As principais dificuldades em atendê-las se concentram, basicamente, nas atitudes de estigma por parte dos profissionais da saúde, nas limitações de horário - em função do trabalho, as mulheres que participaram da pesquisa dificilmente tinham disponibilidade para frequentar o serviço de saúde pela manhã, por exemplo, horário bastante usual de atendimento nos serviços de atenção primária do município - e na abordagem fragmentada de assistência, calcada em cada vez mais especializações, não atendendo integralmente essas mulheres (BRASIL, 2007; 2010).

Os motivos mais citados para busca por algum serviço de saúde foram: a ocorrência de gravidez, a realização do exame preventivo do colo uterino e a busca de preservativos. Em menor número, motivos como "colesterol e glicose altos", ou mesmo, para "cuidar dos dentes" foram referidos.

Os locais mais comentados pelas mulheres para encaminharem suas demandas foram os "postinhos" de saúde. Isso pode significar que as Unidades Básicas de Saúde (UBS) estão, de fato, atuando como porta de entrada aos serviços de saúde, já que é a partir delas que as usuárias serão referenciadas a outros níveis do sistema, 
conforme a necessidade. Apesar disso, insatisfações importantes com os serviços de saúde foram referidas pelas prostitutas. São essas queixas que configuram o segundo aspecto relativo às vulnerabilidades no nível programático. Os maiores descontentamentos foram relacionados à insatisfação com o atendimento, mais especificamente, o modo como são tratadas por alguns profissionais da saúde, independentemente do nível de complexidade do serviço.

Em entrevista, Vanessa (29 anos, oito anos na prostituição) expressou seu desagrado em relação ao modo como é cobrada no hospital: "no hospital eu não gosto muito! A doutora me xinga sempre que eu volto lá. É porque eu não vou muito nas consultas e tal. Eu não gosto disso, ninguém tem que ficar me xingando, eu que sei de mim”. Já Sandra (37 anos, nove anos na prostituição) reclama do atendimento discriminatório que recebe, às vezes, no postinho: "no postinho, às vezes, tem uma ou outra que tu sente que olham com cara feia, quando sabem que sou prostituta, ou coisa assim”.

Situações como essas vêm a somar a uma série de inadequações dos serviços, conforme as já referidas anteriormente, no atendimento a mulheres prostitutas. $\mathrm{O}$ que se configura com isso são comportamentos preconceituosos que punem as mulheres que optaram por ganhar dinheiro com a atividade sexual, comprometendo uma luta que não é apenas por plenos direitos de acesso a serviços de saúde, mas pelo exercício efetivo de direitos civis e políticos (SERAFIM et al., 2002).

A falta de habilidade de certos profissionais da saúde em momentos nos quais poderiam se firmar vínculos consistentes com as prostitutas também merece reflexão. Exemplo disso é a situação contada por Fernanda (28 anos, seis anos na prostituição) em uma tarde de trabalho de campo no bar, na qual conversávamos sobre seus filhos. Ela narrava o dia em que, em trabalho de parto, chegou ao hospital e recebeu advertências da enfermeira pela "irresponsabilidade" de não ter realizado exames de pré-natal: "me deu uma raiva daquela mulher, uma vontade de bater na cara dela! Eu ali tendo o filho, com dor, e ela me cobrando...”.

Percebe-se então que Fernanda sentiu-se desrespeitada em seu momento de parto. $\mathrm{Na}$ medida em que profissionais de saúde impóem julgamento ao comportamento da usuária e às atitudes com sua saúde, perdem a oportunidade de criar vínculo, o que de fato constituiria uma chance de retorno e, consequentemente, integralidade e continuidade na assistência dessas mulheres. Cabe lembrar que esse descontentamento com o atendimento recebido não se refere exclusivamente 
a mulheres que trabalham com prostituição, mas é também relatado por outras

mulheres de segmentos populares (MANDU; SILVA, 1998). Ou seja, tem sido um comportamento usualmente adotado por alguns profissionais da área da saúde, privilegiando a verticalização das relações no atendimento.

No que se refere à situação relatada, não significa afirmar que a não realização do pré-natal devesse ter passado despercebida pelos profissionais, mas talvez o momento (no parto) não tenha sido o mais adequado. Situações como essa acabam atuando como produtoras de uma vulnerabilidade programática, ao passo que não vão ao encontro das necessidades, lógicas e desejos das usuárias.

Em contraponto aos aspectos vulnerabilizantes apontados acima, situações e locais que foram tomados como bom atendimento pelas prostitutas merecem ser descritos. Alguns serviços, como o Programa de Redução de Danos, foram elogiados": "lá atendem a gente bem, já conhecem a gente, dão camisinha, entendem que a gente precisa de mais que os outros" (Raquel, 40 anos, 15 anos na prostituição).

Nas falas das mulheres entrevistadas, observou-se a valorização de comportamentos que facilitam o acesso à saúde - fornecimento de preservativos em maior número, por exemplo -, de atitudes que proporcionam integração e vínculo entre profissionais de saúde e prostitutas e que, para além das formalidades de um atendimento convencional, expressam um sentimento de comprometimento com as usuárias - ir até as prostitutas e recebê-las sem julgamentos quando buscam o serviço.

Diante disso, a estratégia de redução de danos merece ser pensada enquanto tática que, extrapolando sua origem no atendimento a usuários de drogas injetáveis, estende-se à prostituição. Na perspectiva adotada por esse programa, a ideia afirmada é a da busca por uma saúde e bem-estar partindose do princípio fundamental de respeito à liberdade de escolha (BRASIL, 2005; NARDI; RIGONI, 2009). Assim, concorda-se com a afirmação de que a maioria dessas mulheres não deseja serviços de saúde específicos para prostitutas, tendo como base para tanto o princípio da não-discriminação (ABIAS, 2011). Acredita-se que a lógica do Programa Redução de Danos reforça essa ideia de que são os serviços já existentes os que precisam readequar sua estrutura, horários, e mesmo, capacitar seus profissionais para melhor atender as necessidades desse público. 
No sentido de pensar como os serviços de saúde poderiam fomentar os laços fortalecidos em uma rede de cuidados, propõe-se um novo olhar sobre a atividade, $o$ qual possibilite maior aproximação do cotidiano dessas mulheres e das estratégias eficazes que (já) utilizam para lidar com sua saúde. Não considerar a prostituição como "um infortúnio de mulheres desfavorecidas" é um fator fundamental para o avanço dos serviços de saúde no sentido de ir contra o estigma e os preconceitos que sustentam as referidas inadequações.

\section{Considerações finais: possibilidades e limites}

Como reflexão, retomamos a ideia de que o exercício da prostituição em si não pode ser tomado como causa de maior vulnerabilidade à aquisição de doenças, sexuais ou não. $\mathrm{O}$ conceito de vulnerabilidades, enquanto elemento que se constrói e varia a partir de diferentes contextos e relaçôes, precisa então ser considerado. É necessário destacar, ainda, os diferentes recursos acionados pelas mulheres que participaram da pesquisa para lidar com a saúde, os quais caracterizam o que poderíamos chamar de práticas de cuidado em rede.

Essa rede de produção de conhecimento em saúde no cotidiano mostrou-se fundamental para compreender as estratégias eficazes de cuidado utilizadas pelas mulheres. Sejam vindas de casa, da vida na prostituição ou ensinadas e negociadas nos serviços de saúde, essas formas de "cuidado" se articulam, não podendo ser compreendidas no plano apenas individual, mas decisivamente como uma rede na qual são socializadas práticas e a partir da qual são contornadas dificuldades.

Importante notar que esta mesma rede acaba prejudicada em relação às políticas de saúde em função da própria criminalização da prostituição, já que se torna mais difícil pensar em condições de trabalho para prostitutas se a atividade é vista como crime. Tem-se então, a própria legislação produzindo vulnerabilidades em saúde.

Enquanto isso, sob a ótica da saúde, aprimorar e ampliar serviços que reconheçam e se engajem nessa rede de cuidados existentes parece uma boa estratégia inicial a ser pensada. Para tanto, como já foi dito, é fundamental que os mesmos se aproximem do cotidiano das prostitutas e das estratégias que elas (já) utilizam para lidar com sua saúde, fortalecendo-as, assim como favorecendo a formação de ainda outras. Esse (re) olhar significa maior aproximação entre serviços de saúde e prostitutas, possibilitando uma transformação positiva nessa relação. ${ }^{6}$ 


\section{Referências}

ASSOCIAÇÃO BRASILEIRA INTERDISCIPLINAR DE AIDS. Sexualidade $e$ Desenvolvimento: a politica brasileira de resposta ao HIVIAids entre profissionais do sexo. [relatório de pesquisa]. Rio de Janeiro, 2011. Disponível em http://www.abiaids.org. br/_img/media/Relat\%C3\%B3rio\%20Sex\%20e\%20Desenv\%20(site)pt.pdf Acesso em: 20 mar 2012.

AYRES, J.R.C.M. et al. O conceito de vulnerabilidade e as práticas de saúde: novas perspectivas e desafios. In: CZERESNIA, D.; FREITAS, C.M. (Org.). Promoção da saúde: conceitos, reflexões, tendências. Rio de Janeiro: Fiocruz, 2003. p.117-39.

BARRETO, L.C. Prostituição, gênero e sexualidade: hierarquias sociais e enfrentamentos no contexto de Belo Horizonte. 2008. 160 p. Dissertação (Mestrado em Psicologia) Universidade Federal de Minas Gerais, Belo Horizonte, 2008.

BLANCHETTE, T.; SILVA, A.P. da. Amor um real por minuto. Disponível em: http:// www.sxpolitics.org/pt/wp-content/uploads/2009/10/sexualidade-e-economia-thaddeusblanchette-e-ana-paula-da-silva.pdf. Acesso em: 01 jan 2010.

BONET, O.; TAVARES, F. Redes em rede: dimensões intersticiais no sistema de cuidados à saúde. In: PINHEIRO, R.; MATTOS, R. A. (Org.). Gestão em Redes. Práticas de avaliação, formação e participação na saúde. Rio de Janeiro: Cepesc, 2006, p.385-400.

BRAGA, N. de A. Redes sociais de suporte e humanização dos cuidados em saúde. In: DESLANDES, S. F. (Org.). Humanização dos Cuidados em Saúde. Conceitos, dilemas e práticas. Rio de Janeiro: Fiocruz, 2006.

BRASIL. Ministério da Saúde. Coordenação Nacional de DST e Aids. Manual de redução de danos: saúde e cidadania. Brasília: Ministério da Saúde, 2005.

. Secretaria de Atenção à Saúde. Departamento de Ações Programáticas Estratégicas. Área Técnica de Saúde da Mulher. Mulheres contra as DST e Aids. Brasília: Ministério da Saúde, 2007.

. Secretaria de Gestão Estratégica e Participativa. Departamento de Apoio à Gestão Participativa e ao Controle Social. Saúde da mulher: um diálogo aberto e participativo. Brasília: Editora do Ministério da Saúde, 2010.

. Código Penal. Disponível em: http://www.planalto.gov.br/ccivil_03/Decreto-Lei/ Del2848compilado.htm. Acesso em: 25 fev. 2012.

CAVILHA, J. Lugares, fluxos e itinerários no comércio sexual de e na rua: redes sociais na cidade de Florianópolis (SC). Iluminuras, Porto Alegre, v.12, n.27, p.1-39, 2011.

COLVERO, C.A. Mulheres na batalha: performances de gênero em bares com prostituição em Santa Maria. 2010. 82p. Dissertação (Mestrado em Ciências Sociais) - Universidade Federal de Santa Maria, Santa Maria, 2010. 
DANTAS, P.H. Sexo sem beijo: alguns aspectos sobre a baixa prostituição no Rio de Janeiro. Disponível em: <http://www.aldeiaplanetaria.com.br/astrosintese/antropol.htm> Acesso em: 10 jan. 2010.

FONSECA, C. A dupla carreira da mulher prostituta. Revista Estudos Feministas, Rio de Janeiro, v.4, n.1, 1996.

- Família, fofoca e honra: etnografia de relações de gênero e violência em grupos populares. Porto Alegre: UFRGS, 2000.

GUIMARÃES, K.; MERCHÁN-HAMANN, E. Comercializando fantasias: a representação social da prostituição, dilemas da profissão e a construção da cidadania. Rev. Estudos Feministas, Florianópolis, v.13, n.3, p.525-544, 2005.

LACERDA, A.; VALLA, V.V. Um outro olhar sobre a construção social da demanda a partir da dádiva e das práticas de saúde. In: PINHEIRO, R.; MATTOS, R. A. (Org.) Construção Social da Demanda. Direito à saúde - trabalho em equipe - participação e espaços públicos. Rio de Janeiro: Cepesc, 2005, p.281-294.

MANDU, E.N.T.; SILVA, G.B. da. Assistência pública à saúde: mulheres com a palavra. Rev. esc. enferm. USP, São Paulo, v.32, n.3, p. 218-230, 1998.

MOURA, A.D.A.et al . O comportamento de prostitutas em tempos de aids e outras doenças sexualmente transmissíveis: como estão se prevenindo? Texto contexto - Enferm., Florianópolis, v. 19, n.3, Set. 2010.

NARDI, H.C.; RIGONI, R. de Q. Mapeando programas de redução de danos da Região Metropolitana de Porto Alegre, Rio Grande do Sul, Brasil. Cad. Saúde Pública, Rio de Janeiro, v.25, n.2, p.382-392, 2009.

OLIVAR, J.M.N. Guerras, trânsitos e apropriaçôes: políticas da prostituição feminina a partir das experiências de quatro mulheres militantes em Porto Alegre. 2010, 385p. Tese (Doutorado em Antropologia Social) - Universidade Federal do Rio Grande do Sul, Porto Alegre, 2010.

. Entre Nilce, a prostituta, e Isabel, a Princesa. Sobre redes, relações e arcabouços libertários. Iluminuras, Porto Alegre, v.12, n.27, p.1-25, 2011.

OLTRAMARI, L.C.; CAMARGO, B.V. Representações sociais de profissionais do sexo sobre prevenção de doenças sexualmente transmissíveis e contracepção. Psicologia, São Paulo, v.6, n.2, p.75-87, 2004.

PASINI, E. Corpos em evidência: pontos em ruas, mundos em pontos: a prostituição na região da Rua Augusta em São Paulo. 2000, 168p. Dissertação (Mestrado em Antropologia Social) - Universidade Estadual de Campinas, Campinas, 2000.

. Sexo para quase todos: a prostituição feminina na Vila Mimosa. Cadernos Pagu, Campinas, n.25, p.185-216, 2005. 
PINHEIRO, R.; GUIZARDI, F.L. Quando dádiva se transforma em saúde: algumas questôes sobre a integralidade e o cuidado nas relações entre sociedade e Estado. In: PINHEIRO, R.; MATTOS, R.A. (Org.). Cuidado. As fronteiras da integralidade. Rio de Janeiro: Cepesc, 2008, p.39-58.

PISCITELLI, A. Corporalidade em confronto: brasileiras na indústria do sexo na Espanha. Rev. bras. Ci. Soc., São Paulo, v.22, n.64, p.17-32, 2007.

. Prostituição e trabalho. In: LIMA, M.E.B. de et al. (Org.). Transformando as relaçôes trabalho e cidadania, produção, reprodução e sexualidade. Salvador: UFBA, v.1, p.183-195, 2007.

RODRIGUES, M.T. A prostituição no Brasil contemporâneo: um trabalho como outro qualquer? Rev. katálysis, Florianópolis, v.12, n.1, p.68-76, 2009.

RUSSO, G. No labirinto da prostituição: o dinheiro e seus aspectos simbólicos. Cad. CRH, Salvador, v. 20, n.51, p.497-514, 2007.

SARTI, C.A. A família como espelho: um estudo sobre a moral dos pobres. 2. ed. rev. São Paulo: Cortez, 1996, 152p.

SERAFIM, D. et al. Profissionais do sexo: documento referencial para ações de prevenção das DST e da Aids. Brasília: Ministério da Saúde, 2002.

SILVA JUNIOR, A.G.; ALVES, C.A.; ALVES, M.G.M. Entre tramas e redes: cuidado e integralidade. In: PINHEIRO, R.; MATTOS, R. A. (Org.) Construção Social da Demanda. Direito à saúde - trabalho em equipe - participação e espaços públicos. Rio de Janeiro: Cepesc, 2005, p.77-90.

TEDESCO, L. da L. Explorando o negócio do sexo: uma etnografia sobre as relações afetivas e comerciais entre prostitutas e agenciadores em Porto Alegre. 2008. 208 p. Dissertação (Mestrado em Antropologia Social) - Universidade Federal do Rio Grande do Sul, Porto Alegre, 2008.

\section{Notas}

${ }^{1}$ A presente pesquisa foi realizada com vistas à dissertação de Mestrado em Saúde Coletiva da Universidade do Vale do Rio dos Sinos (UNISINOS), defendida por Priscila de Oliveira Bolzan Bonadiman, e não contou com financiamentos.

${ }^{2}$ Todas as mulheres que responderam às entrevistas assinaram um termo de consentimento livre e esclarecido (TCLE), previamente aprovado pelo Comitê de Ética da UNISINOS, em conformidade com a Resolução CONEP no 196/96. Todos os nomes foram substituídos no corpo do texto, no intuito de preservar as identidades das pessoas que participaram da pesquisa.

3 "Segmentos populares" é utilizado aqui em relação ao espaço social que esses grupos ocupam na sociedade. Conforme aponta Claudia Fonseca (2000), o "popular" se refere principalmente a populaçôes urbanas de baixa renda, mas não se restringe a uma definição exclusivamente em termos socioeconômicos, levando em consideração olhares do mundo "a partir de baixo"; significados, valores e dinâmicas culturais que produzem uma alteridade em relação a culturas e grupos dominantes/hegemônicos. 
${ }^{4} \mathrm{O}$ autor aponta também a questão da violência em sua tese. Para ele, a valorização social negativa da puta é o que acaba por justificar formas de discriminação e violência dirigidas às prostitutas, produzindo também a autodepreciação e desvalorização de seu corpo e sexo. Embora na presente pesquisa não se tenha encontrado relatos a respeito de situaçôes de violência, cabe salientar que estamos atentas para sua alta frequência no âmbito da prostituição, conforme demonstram outros trabalhos, como o de Olivar (2010). Considera-se ainda que, no contexto específico deste estudo, talvez as próprias prostitutas não identifiquem em seu cotidiano situações de violência de gênero, pelo fato de não percebê-las como tal, o que não significa que essas situações não existam, das mais diversas formas.

${ }^{5}$ Vale ressaltar que a pesquisadora já havia atuado nesse programa e que o reconhecimento desse fato pelas mulheres pode interferir em suas falas acerca da equipe da redução de danos.

${ }^{6}$ P.O.B. Bonadiman realizou o trabalho de campo. Todas as autoras participaram igualmente da elaboração do artigo. Declara-se que não existem conflitos de interesse em relação ao presente texto. 


\section{Abstract}

Health practices among prostitutes from popular segments in the city of Santa Maria$R S$ : the care network

The current research analyzed the health perceptions and practices among bar prostitutes in the city of Santa Maria, Rio Grande do Sul. For this reason, those women's health practices and care and how they related to health services were investigated through techniques of participant observation and semi-structured interviews. Among women, in the surveyed context, it was identified the "care network" as a health care strategy, which is triggered in different situations, as the ones that involve daily work. It is concluded that the established nets exceed the individual level of care, configuring health knowledge production, articulating decisively in response to vulnerabilities, socializing practices and circumventing difficulties.

Key words: female prostitution; vulnerabilities; care network. 